\title{
DESDE EL MARGEN. IDENTIDAD SOCIAL DE GRUPOS MINORITARIOS E INTERVENCIONES VISUALES EN EL ESPACIO PÚBLICO
}

\author{
DESDE A MARGEM. IDENTIDADE SOCIAL DE GRUPOS \\ MINORITÁRIOS E INTERVENÇÕES VISUAIS NO ESPAÇO PÚBLICO
}

Carolina Anabel Bravi

Universidad Nacional del Litoral e Universidad Autónoma de Entre Ríos, Argentina

\section{Resumo}

Este trabalho analisa dois tipos de intervenção visual (grafite e cartazes) elaborados por grupos de pessoas afetadas pelas inundações de 2003 e 2007 na cidade de Santa Fé (Argentina), com o fito de refletir sobre o papel das imagens na construção da identidade social destes grupos minoritários. Para tanto, começa apresentando o espaço público como lócus onde diferentes setores sociais manifestam lutas simbólicas para impor seu domínio. Neste contexto se reconhece que o grafite se trata de uma prática contestatária que canaliza e enaltece a voz dos setores subalternos. Assim, o presente artigo apresenta a problemática das inundações na cidade de Santa Fé e analisa as produções desde a perspectiva dos Estudos Visuais. Em seguida, incorpora as contribuições da Psicologia Social para refletir sobre as relações intergrupos e os processos de construção da auto-identidade de grupo. Por último, destaca como estas mensagens estético-político colaboraram no desenvolvimento desses processos.

Palavras-chave: Representações sociais. Identidade social. Grafite. Grupos minoritários. Imagens visuais. 


\section{Resumen}

Este trabajo analiza dos tipos de intervenciones visuales (graffitis y carteles) elaborados por grupos de personas afectadas por las inundaciones de 2003 y 2007 en la ciudad de Santa Fe (Argentina) a fin de reflexionar sobre el rol de las imágenes en la construcción de la identidad social de estos grupos minoritarios. Para ello se comienza presentando al espacio público como un ámbito donde los distintos sectores sociales despliegan luchas simbólicas por imponer su dominio. En este contexto se reconoce que el graffiti es práctica contestataria que canaliza y exalta la voz de los sectores subalternos. Luego se presenta la problemática de las inundaciones en esta ciudad (Santa $\mathrm{Fe}$ ) y se analizan las producciones desde la perspectiva de los Estudios Visuales. Seguidamente se incorporan los aportes de la Psicología Social para reflexionar sobre las relaciones intergrupales y los procesos de construcción de la auto-identidad grupal. Finalmente se destaca como estos mensajes estético-políticos colaboraron en el desarrollo de estos procesos.

Palabras clave: Representaciones sociales. Identidad social. Graffitis. Grupos minoritarios. Imágenes visuales.

\section{Introducción: El espacio público}

El espacio público es un escenario donde se despliegan prácticas diversas. Es un lugar que congrega a la colectividad, que condensa y expande saberes y representaciones. Es también un ámbito de participación democrática y de construcción de identidades. Es, al mismo tiempo el sitio donde la comunidad se encuentra, comparte, y celebra; y también donde debate, resiste y lucha.

Desde un punto de vista teórico es un concepto que presenta una doble dimensión, como espacio físico (urbis) se refiere a los lugares comunes como calles, plazas, parques, avenidas, etc., y como ámbito político (civitas) alude a la esfera de la participación social (ROSSI, 1976). Para Habermas (1986) el espacio público es el lugar donde surge la opinión pública. Establece sus orígenes en el momento de consolidación de la burguesía europea a fines del 
siglo XVII y comienzos del XVIII, y lo describe como una agrupación de intereses de las personas privadas de carácter civil, no estatal. El espacio público, motorizado por la prensa, era entonces para el autor una esfera que reunía a los ciudadanos para manifestar sus opiniones respecto de cuestiones relativas a la acción del Estado y la sociedad.

Entendiendo que lo espacial está indisolublemente unido a lo político, Massey $(2005)^{\mathrm{i}}$ lo describe como una arena conformada por las interrelaciones entre grupos y actores sociales, como producto y como parte de los vínculos sociales que se generan dentro de él, como un ámbito donde conviven voces diversas, como un estadio dinámico y en formación, nunca cerrado. Territorios e identidades son para la autora elementos constituyentes de la superficie política, elaborados en y por el espacio público.

Pensar la identidad en estos términos implica entenderla como una construcción relacional que se manifiesta en los diferentes discursos sociales y que conjuga historia, deseos, miradas; pasados, presentes y futuros. Desde esta misma perspectiva, Giménez (2009) sostiene que la identidad es una representación social que surge a partir de la percepción de las diferencias entre las personas y del reconocimiento como tal de los demás, de la pertenencia a ciertos grupos, y de la existencia de una valoración (positiva o negativa). Todas estas instancias, que se articulan en el proceso de construcción de las identidades sociales, se desarrollan en el espacio público, en contacto con los otros y a la vista de todos.

El espacio púbico es además el lugar donde el poder despliega su voluntad de dominio, ya sea mediante la actividad del mercado inmobiliario y la reglamentación urbana que inciden en la configuración de los espacios físicos, como a través de los discursos hegemónicos, que establecen el marco de lo que es posible ser dicho, pensado o realizado. En las últimas décadas el espacio público, como el ámbito del pensamiento crítico y la libre participación ciudadana ha dejado de estar relacionado exclusivamente con los medios de comunicación incorporando instancias como el ciberespacio. Sin dejar de reconocer el impacto que han tenido estas nuevas prácticas en lo político, lo económico, lo social, etc., las calles de la ciudad siguen siendo un sitio privilegiado para la expresión de las voces que forman parte de los discursos dominantes y las que no.

Como explica Kozak (2004), durante la última mitad del siglo XX las paredes de las ciudades argentinas se llenaron de inscripciones políticas y convirtiéndose en una parte más del paisaje urbano. Si bien este tipo de pintadas tienen una historia previa que la autora retoma a partir de la frase de Sarmiento tras su exilio en Chile, "las ideas no se matan", desde la 
década del cuarenta, sostiene, han estado presentes en la mayoría de los hechos históricos relevantes. ${ }^{\text {ii }}$

Además de la fuerte impronta política que tiene la acción, trasgresora y contestaria, de pintar leyendas en las paredes, en las últimas décadas del siglo XX, el graffiti se vio influenciado por las culturas audiovisuales, lo que se pudo apreciar en la incorporación de imágenes y en las referencias a otras producciones culturales como la música, la publicidad, los programas de televisión, etc. Esta tendencia tomo una nueva forma con la explosión del esténcil ${ }^{i i i}$ en la ciudad de Buenos Aires luego de la crisis de 2001. Allí, mediante esta técnica, se pusieron en juego el imaginario de la cultura popular y de los medios masivos, cuestionando el sistema y proponiendo un modo diferente de comunicación. A diferencia de las leyendas anteriores, que, como explica la autora, eran para ser leídas; en este caso el sentido del mensaje surgía de la asociación entre la imagen y la palabra. Además, estas pequeñas figuras estaban incorporadas al escenario de la ciudad, escondidas entre carteles, publicidades y pintadas tradicionales; y sorprendían al peatón con humor e ironía. Así se generaba un diálogo basado en la complicidad y los saberes compartidos, que cuestionaba el accionar de los medios de comunicación, revelaba contradicciones y desigualdades del sistema capitalista, denunciaba la violencia policial, la precarización laboral, los delitos cometidos durante la última dictadura militar, etc. ${ }^{\text {iv }}$

Otras formas de intervención visual desarrolladas en la ciudad en esos años fueron los afiches, que, reformulando la tradición de la cartelería urbana, se presentaban como una práctica contestaria del mismo tipo que el graffiti. Las principales diferencias entre ambos eran: el soporte (en un caso la imagen se construía sobre la pared, en el otro sobre un papel), y la técnica (esténcil, fotomontaje, etc.). Estas expresiones, en el contexto de la Argentina posterior a 2001, fueron parte de una práctica política que intentaba visibilizar pensamientos, ideas e interpretaciones que no solo no formaban parte de los discursos hegemónicos, sino que además los cuestionaban.

Este trabajo analiza dos intervenciones que se enmarcan en este contexto, y que utilizaron el espacio físico de la ciudad como soporte para plasmar representaciones y para instalar reclamos en la agenda pública: los carteles y los graffitis (esténcil) producidos por grupos de personas afectadas por las inundaciones de 2003 y 2007 en la ciudad de Santa Fe 
(Argentina). A partir de ello se propone reflexionar sobre el rol que tuvieron estas prácticas (artísticas y políticas) en la construcción de la identidad grupal, en la visibilización de sus reclamos y la instalación en la agenda pública de una problemática tan compleja y reiterada como son las inundaciones.

Para llevar adelante este estudio se trabaja a partir dos perspectivas, una que aborda el análisis de la imagen, y la otra la identidad; que tienen en común el concepto de "representación". Desde los Estudios Visuales se propone el abordaje de la imagen entendida como una "presentación" y una "representación". El primer caso se refiere a la capacidad de la imagen para generar su propia significación a partir de una experiencia predominantemente visual. La imagen se presenta, es decir se exhibe, se expone, se muestra. Esto la asemeja a la representación teatral, donde lo más importante no es la semejanza con la realidad sino la capacidad que tenga para conmover al espectador, y se la estudia para dar cuenta, en términos de Didi Huberman (2006), de los modos en que da acceso a algo, que "resuena" con lo real. El segundo, alude a la facultad de traer al presente algo ausente, o de ocupar el lugar de, como sucede en la representación política. En este caso se analizan las relaciones que establece con el referente, sus propósitos y su potencial ideológico.

Los conceptos de "identidad social” y "representación social” son tomados, siguiendo lo planteado por Giménez (2009) conjuntamente, si bien se reconoce que cada uno de ellos tiene un origen teórico y un campo disciplinar distinto, (uno vinculado a la Psicología Social, y el otro a los Estudios Culturales ${ }^{v}$ ). Es decir que se entiende a la identidad como una representación social, construida en el marco de la cultura e interiorizada por los sujetos. Para ello propone trabajar desde un enfoque interdisciplinario, que, en este caso se manifiesta en la integración de los aportes de Psicología Social (TAJFEL, 1984; PÁEZ, 1987) y los Estudios Visuales (MIRZOEFF, 2003, MITCHELL, 2003).

\section{La problemática de las inundaciones}

La ciudad de Santa Fe (Argentina) se encuentra ubicada en la confluencia de dos grandes ríos: el Paraná y el Salado. Desde su fundación en 1573, su destino ha estado marcado por el ritmo cíclico de las inundaciones. Desde mediados del siglo XX se han buscado soluciones a esta problemática que afecta mayormente a quienes viven en terrenos de cotas bajas en la periferia urbana o bien a la vera de los ríos. Para controlarlo se creó un 
sistema de defensas ${ }^{\mathrm{vi}}$ que consiste en terraplenes emplazados en sitios estratégicos que, siguiendo los cursos de água, van rodeando la ciudad.

El primero de ellos se construyó en el borde oeste sobre el río Salado en la década del cuarenta y a partir de esta obra se consolidó un amplio sector urbano que se fue ocupado por barrios de sectores medios y bajos. La siguiente intervención fueron las defensas levantadas en la década del noventa en la zona costera ubicada al este de la ciudad. Asimismo, en el oeste, en esos años se comenzó a construir una gran obra de circunvalación vial y contención hídrica continuando el terraplén anterior.

En 2003 la ciudad de Santa Fe soportó un gran creciente del río Salado ${ }^{\text {vii }}$ que dejó un saldo de 22 muertos, más de 130.000 personas evacuadas de sus hogares y un tercio de la ciudad bajo agua. No hubo advertencias previas, ni plan de evacuación que organizara el traslado de las personas y sus bienes, por lo tanto, las pérdidas fueron enormes, desde el punto de vista económico y simbólico o afectivo.

En 2007 se produjo nuevamente otra inundación como consecuencia de las copiosas lluvias (y otros factores asociados ${ }^{\text {viii) }}$ y afectó la misma porción de territorio urbano y una extensa zona rural, pero a diferencia del caso anterior, en esta oportunidad el agua se retiró más rápidamente y ocasionó menores daños.

Estos eventos, en particular el de 2003, produjeron una importante movilización social que se plasmó en la constitución de grupos de personas afectadas que demandaban que los responsables políticos de esta tragedia fueran juzgados y que se compensara económicamente a las víctimas por las pérdidas sufridas.

Siendo que la inundación en esta región no es un fenómeno nuevo, una pregunta que surge es porque esta vez, este fenómeno conocido y reiterado, generó un movimiento social tan significativo que suscitó la adhesión de otras organizaciones y personas, y la problemática de la inundación se instaló como un reclamo que debía ser imperiosamente resuelto. Algunas respuestas a estas preguntas pueden comenzar a delinearse al reconocer las diferencias existentes entre las inundaciones tradicionales, ocurridas durante de la segunda mitad del siglo XX (1966, 1977,1983, 1992, 1998), y las más recientes.

Las áreas anegadas anteriormente eran mayormente zonas costeras, suburbanas y rurales, cuya población estable era de origen rural y de escasos recursos. Estos territorios y su 
población no eran considerados urbanos y no estaban integrados a la dinámica de la ciudad, además, y como consecuencia de ello, la cantidad de personas y viviendas afectadas era menor (si bien los daños en la infraestructura fueron importantes). En cambio, en los eventos más recientes el mayor impacto se produjo dentro de la ciudad con el anegamiento de miles de viviendas, instituciones y equipamientos como escuelas, hospitales, parques, clubes, etc. Respecto de la composición social, la mayoría los damnificados de 2003 pertenecían a sectores bajos, y en menor medida a estratos medios (CEPAL, 2003). Esto dio como resultado cierta heterogeneidad, que se compensó con la presencia de un elemento en común que aglutinó y dio identidad al colectivo de las personas inundadas: haber sufrido la misma tragedia, y pertenecer a la ciudad, es decir ser población plenamente integrada a la vida urbana.

Las representaciones sociales que existían antes de estos eventos, no incluían esta caracterización. La identidad social de las personas inundadas, analizada desde la antropología (ULLBERG, 2013), y plasmada en múltiples expresiones culturales como filmes, poemas, canciones, etc. (BRAVI, 2013) destacaba características como la vida en contacto con la naturaleza, la pobreza, las carencias, e incluso en algunos casos existía (y existe) una mirada condenatoria sobre estas personas que son vistas como haraganes, aprovechadores, ladinos y acostumbrados a las prácticas clientelares. De este modo se construía una argumentación que los señalaba como culpables de la situación en que estaban, por asentar sus viviendas en sectores bajos, por no estar integrados a la ciudad, etc. (ULLBERG, 2013).

La afectación de la ciudad presentó un escenario diferente y un sujeto diferente. Además, la diferenciación de estas inundaciones respecto de las anteriores fue enfatizada por la acción (e inacción) del Estado para llevar adelante las tareas de prevención, como la no finalización de la obra de contención, la no construcción de defensas provisorias, la falta de alerta temprana, de ordenamiento y organización de la evacuación de la población, etc. Este conjunto de factores permitió entender, conceptualizar y enmarcar este evento hídrico como una tragedia originada por la incapacidad del Estado para hacer frente a la situación, y no como un desastre natural, producto de la creciente de los ríos, como era concebida anteriormente.

En este sentido es interesante destacar la participación activa que tuvieron las minorías pertenecientes a sectores medios en la presentación de este acontecimiento como una \begin{tabular}{l|l} 
Revista RBBA & Revista Binacional Brasil Argentina
\end{tabular} 
catástrofe política, y en la organización y posicionamiento social del reclamo ${ }^{\mathrm{ix}}$. La acción de estos grupos, con mayores posibilidades y herramientas simbólicas para instalar sus reclamos como demandas genuinas, favoreció la adhesión de muchos no inundados al tiempo que posicionó su causa junto a otras socialmente legitimadas como el pedido de verdad y justicia de los organismos de derechos humanos, y las demandas de las asambleas populares surgidas luego de la crisis de 2001.

\section{Los carteles: denuncia e ironía}

Las organizaciones más representativas de los movimientos de personas afectadas por la inundación fueron dos: la Carpa Negra de la Memoria (que instaló una carpa frente a la Casa de Gobierno provincial y luchaba por conseguir una reparación económica por las pérdidas,) y la Marcha de las Antorchas (que todos los días martes organizaba rondas con velas encendidas por la Plaza de Mayo, para pedir el juicio a los responsables políticos de la tragedia). También hubo otras como la Coordinadora de Barrios Inundados y la Asamblea Permanente de Afectados por la Inundación. Todas estas agrupaciones utilizaron en sus marchas y manifestaciones una serie de afiches, volantes y carteles mediante los cuales expresaban su pedido de memoria y justicia, y su sentimiento de dolor y desamparo frente al abandono del Estado (GUALA, 2005). Estos materiales incluso se repartían en los actos, organizados para visibilizar la problemática y convocar a la participación, se pegaban en la vía pública, en las vidrieras de los negocios (con permiso de sus dueños), en escuelas, facultades, oficinas públicas, etc.

Los carteles que tuvieron mayor visibilidad e impacto fueron los dos que se analizan ${ }^{\mathrm{x}}$. Uno de ellos se construyó sobre la base de la fotografía de la inauguración de la obra de defensa hídrica y circunvalación de la ciudad que estaba inconclusa al momento de la creciente (pero aun así había sido inaugurada, dando a los vecinos una falsa sensación de seguridad). En esta imagen se observa un conjunto de funcionarios descubriendo una placa y se le agrega una leyenda: "Los Inundadores. Para que no se sigan riendo de nosotros. Juicio y castigo", acompañada por la lista de nombres y apellidos de las personas retratadas.

El otro afiche es un fotomontaje producido a partir de la fotografía de la tapa del disco “La argentinidad al palo" del grupo Bersuit Vergarabat (2004). En él se cambia el rostro de Revista RBBA $\mid$ Revista Binacional Brasil Argentina 
los músicos por el de los políticos responsables de la tragedia, se los representa con los pies en el agua, y se establece un paralelo con título para denunciar la impunidad.

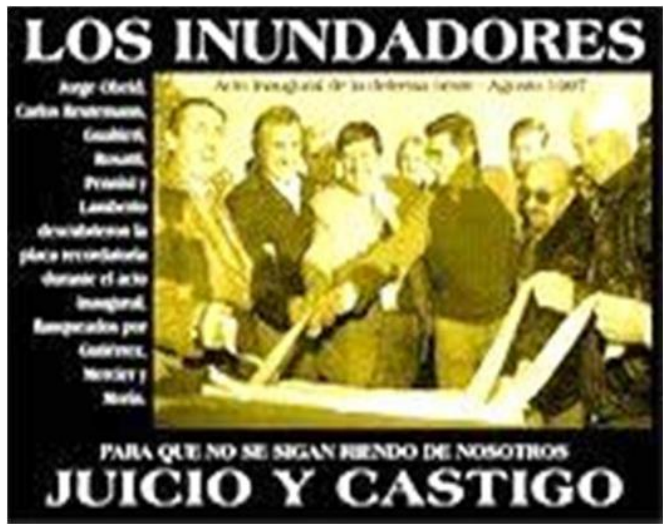

Figura 1. Afiche Los Inundadores

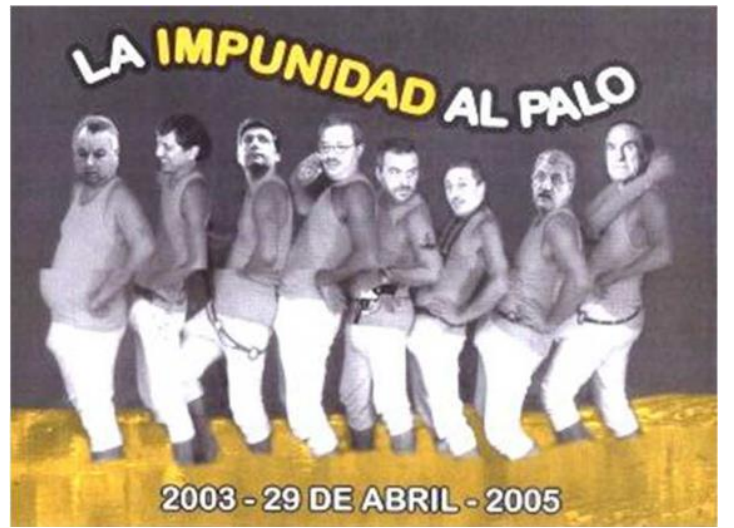

Figura 2. Afiche La impunidad

En "Los inundadores" la fotografía es la prueba de un hecho ilícito: inaugurar una obra sin haberla finalizado. La recuperación de este acontecimiento tiene como objetivo señalar a los responsables y mostrar la acción que se condena. La imagen trae al presente (re-presenta) un hecho olvidado por la mayoría de la población, y se presenta dando testimonio de lo ocurrido, reforzando el argumento de que las causas de la tragedia fueron políticas ${ }^{\mathrm{xi}}$. De este modo el afiche pone en escena la figura del otro, lo trae al presente mediante la foto, los nombres y apellidos, y el rótulo de "inundadores", y al hacerlo crea una imagen de quien emite el mensaje, que se presenta como alguien que no se deja engañar, que es moralmente superior a los acusados, que reclama y lucha por sus derechos, que acusa, señala y critica.

El segundo afiche también se construye a partir de una imagen previa, pero esta vez es una fotografía conocida por buena parte de la población, y el sentido surge de la asociación entre los términos: argentinidad-impunidad, y de la alusión a una banda de rock, caracterizada por sus canciones críticas al sistema. La elección la tapa de su disco, como el referente sobre el cual se construye un nuevo discurso paródico, supone un espectador familiarizado con esta música, que se caracteriza por ser un consumo típico de los sectores juveniles medios urbanos. De este modo los enunciadores se diferenciaban de las personas afectadas por las inundaciones anteriores que habitaban en zonas rurales, pertenecían a sectores populares y tenían otros consumos culturales asociados al folclore. 
Por otra parte, el uso del fotomontaje tenía puntos de contacto con las tapas del periódico Página 12 de la década del noventa. Estas eran imágenes construidas a partir del humor y la ironía que se alejaban del "discurso real" y creaban un vínculo entre el emisor y los lectores basado en el reconocimiento de los saberes compartidos. En el caso de este afiche la identificación con el lector (observador) también se producía sobre la base de este consumo cultural asociado a los sectores medios urbanos, y la complicidad se establecía con todos ellos, hayan o no sufrido la inundación.

Uno de los motivos por los cuales estos carteles resultaron tan significativos para la lucha de las agrupaciones de personas afectadas por la inundación fue que ambos presentaron sus demandas como legitimas empleando un esquema argumental conocido: ciudadanos indefensos contra un Estado incapaz de cuidarlos o un Estado que acciona en contra de la población. Este planteo tiene antecedentes históricos, en otros reclamos sociales anteriores como el pedido de memoria y justicia de los familiares y víctimas de la dictadura militar, el cuestionamiento de la represión policial durante los acontecimientos de diciembre de 2001, los hechos de corrupción en el Estado durante el gobierno menemista (venta de armas, valijas diplomáticas, etc.), entre otros. De este modo, se logró crear un "nosotros" ampliado sumaba adhesiones destacando los patrones simbólico - culturales compartidos, y que incluía a quienes resultaron afectados por la inundación y a los sectores medios que, sin haber tenido agua en sus viviendas, apoyaron el reclamo por considerarlo justo.

\section{Los graffiti (estencil)}

A inicios de los 2000, y siguiendo una tendencia que se expandió por muchas ciudades argentinas, en las paredes de la ciudad de Santa $\mathrm{Fe}$ aparecieron pequeñas inscripciones realizadas con la técnica del esténcil que hablaban sobre la situación social, la política, los clubes de fútbol, la música, y sobre la inundación de 2003 y 2007, entre otros. Eran imágenes de figuras simplificadas que apelaban conocimientos compartidos para generar un mensaje que buscaba desde el humor, provocar una reflexión crítica o proponer una nueva mirada sobre un hecho conocido.

Los graffitis (esténcil) de la inundación abordaron la dimensión política, como por ejemplo la reformulación del emblema provincial, e ironizaron sobre la situación de soportar 
crecientes reiteradas, como los dibujos de los peces, buzos, barquitos de papel, etc. Comparándolos con los casos anteriores se observa que afiches y graffitis, apelan al humor para plantear una denuncia, identifican al Estado como el responsable y se insertan en el espacio público como prácticas trasgresoras y de protesta que se realizan desde el margen. Pero cada uno lo hizo de manera particular.

Los graffitis, a diferencia de los carteles, establecían una relación especial con el entorno donde se estampaban interactuando con otros elementos urbanos como postes de luz, cartelería, otras pintadas, etc. por ello el lugar donde se los colocaba resulta un dato importante que ayuda a comprender su sentido. Asimismo, estos pequeños dibujos no siempre presentaban un mensaje claro y evidente, sino que muchos de ellos generaban en el observador un cambio de percepción, o un diálogo basado en las experiencias y los saberes en común. Por otra parte, estas imágenes no se convirtieron en banderas de la lucha. Es decir, no estaban subordinadas al proyecto ideológico, sino que aunaban de manera conjunta la búsqueda estética y la política. Por lo tanto, no buscaban un reconocimiento o una legitimación social, solamente intentaban filtrarse por entre los múltiples mensajes presentes en la ciudad, para sorprender al peatón con un guiño y activar el entendimiento proponiendo un nuevo punto de vista.

Por ejemplo, el esténcil que retoma el emblema de la bandera provincial y lo reelabora en clave satírica. Para ello se apela a dos estrategias, cambia la palabra "invencible" por "inundable" y cambia las tres lanzas cruzadas por tres remos. El texto y su ubicación en forma oval recomponen el sentido de la imagen, asociándola con el escudo. No es casual que haya sido pintado en las cercanías de la Casa de Gobierno de la provincia, con lo cual refuerza el señalamiento de la responsabilidad del Estado en este evento trágico. En este sentido la imagen recoge el reclamo de justicia de las organizaciones de personas afectadas por la inundación y representa (ocupa el lugar de) una apelación al Estado provincial y un reconocimiento de las características geográficas de la región. 


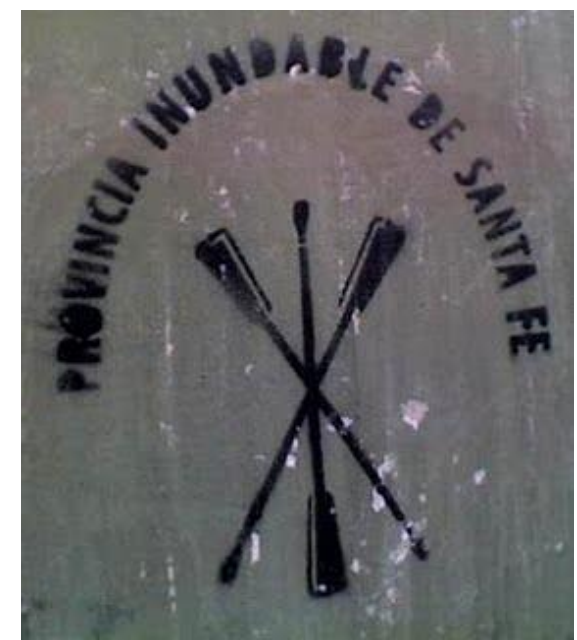

Figura 3. Emblema modificado

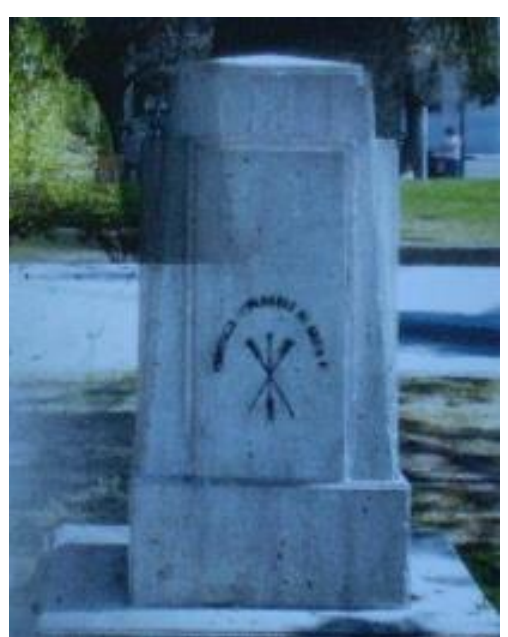

Figura 4. Inserción en el espacio público

Por otra parte, el juego de palabras pone en primer plano la condición baja de este territorio advirtiendo que, aún en un entorno urbano, existe siempre a la posibilidad de anegamiento. Esto cambiaba el lugar tradicional de la inundación que pasaba de ser un fenómeno suburbano propio de quienes habitaban en la costa de los ríos, a ser un problema urbano que afectaba a quienes vivían en la ciudad.

Al intervenir sobre un símbolo reconocido, este graffiti se presentó como una protesta no institucionalizada que expresaba lo que no tenía lugar dentro de (la mayoría) de los discursos hegemónicos. Esto le permitió mayor libertad creativa que dio como resultado un mensaje articulado y rico, que no denunciaba de manera panfletaria (como por ejemplo las escrituras con aerosol en las paredes) sino que llamaba a la reflexión mediante recursos estéticos que, sin decirlo de manera evidente, aludían claramente a una posición crítica.

Además de este esta propuesta, de claro contenido político, hubo otras orientadas al humor. Por ejemplo, una serie de esténciles de peces, buzos, y otras figuras, entre los que se destacan estas tres imágenes, que se reconstruyen. 

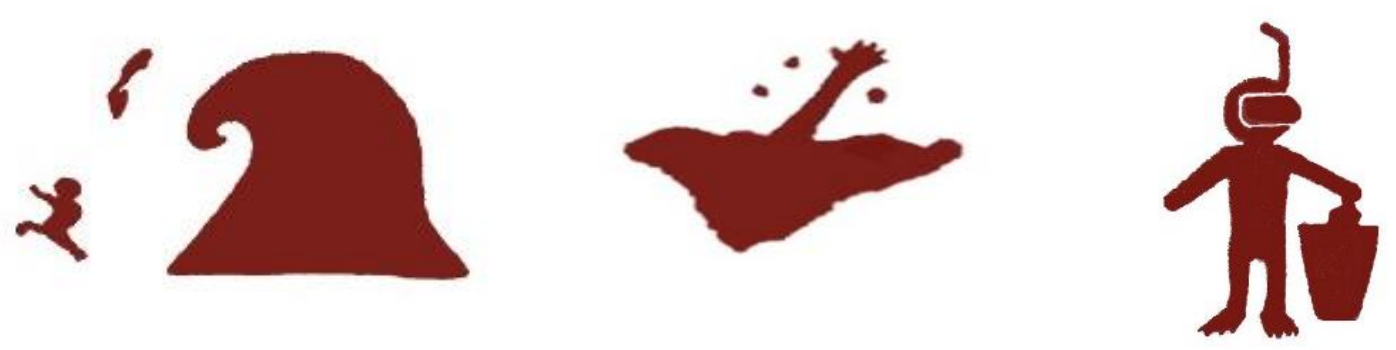

\section{Figura 5. Esténcil graffitis}

Estos graffitis aparecidos en el centro de la ciudad, tomaban como punto de partida una figura humana simplificada, y contaban situaciones semejantes a las vividas por los afectados por la inundación. La gran ola que persigue al pequeño sujeto expresaba lo inesperado que fue la llegada del agua y la indefensión frente a la naturaleza; la mano que emerge puede entenderse como un pedido de auxilio, y el buzo que tira la basura en el cesto se refiere al tiempo de la permanencia del agua, y de la reiteración. Como si la condición de inundable hubiera venido para quedarse. Esta mezcla de lo cotidiano del acto de arrojar la basura, con lo excepcional del ambiente, expone también el impacto que significó la inundación en la rutina diaria de las personas afectadas.

Estas imágenes representan a los damnificados y las situaciones que vivieron, retratándolos desde el humor, la exageración y el absurdo. Para ello construyen un "otro" que, en este caso es el agua, que se representa en forma de ola, de río o de fondo sobre el cual aparecen las figuras. El agua está en todos lados y lo cubre todo; y aunque no se vea, se sabe que siempre esta allí. De este modo personas, situaciones y agua conviven en una representación que vuelve la mirada sobre lo cotidiano, sobre la angustia de no saberse seguro, sobre el temor de que la tragedia vuelva a repetirse.

Estas imágenes se presentan como intervenciones estéticas que orientan la mirada hacia el la construcción visual para, desde allí, construir un discurso político que subyace bajo la superficie de la imagen. La impronta artística permite también generar un mensaje abierto que integra a inundados y no inundados, no desde la adhesión a la causa, sino desde la empatía. Es decir que son representaciones construidas desde el plano afectivo, que intentan obtener la adhesión de los espectadores generando emociones, no convenciéndolos con argumentos racionales. Este tipo de práctica que unía lo político y lo artístico formó parte de una tendencia que se desarrolló en los años posteriores a 2001, que se caracterizó por la 
colectivización de las acciones, la fusión entre arte y política, la intervención en el espacio público, y la recuperación de la memoria, entre otras (GIUNTA, 2009).

De esta manera los graffitis analizados pusieron en escena la voz de un sector de las clases medias ${ }^{\mathrm{xii}}$ afectada por la inundación, que desde un lugar que se ubicaba en el medio de: lo subalterno (como lo son los afectados por la inundación) por un lado, y lo que, sin llegar a ser hegemónico es una práctica contestataria aceptada y reconocida como son los esténciles, por el otro. Es decir, eran expresiones de reclamo y de denuncia, que no ponían en crisis los sistemas simbólicos, no escandalizaban, no irrumpían violentamente en la escena urbana, pero de manera casi imperceptible, interceptaban la mirada del espectador desprevenido denunciando y recordando lo que pasó, y lo que pude volver a pasar.

\section{Construcción de la identidad social}

¿De qué manera estas imágenes y estas prácticas creativas de elaboración de mensajes visuales y de intervención urbana incidieron en la construcción de la auto identidad (o auto representación) de las personas afectadas por las inundaciones? ¿Qué rol tuvieron estas imágenes al momento de instalar en el espacio público una problemática propia de un grupo minoritario?

Para reflexionar sobre estas cuestiones se parte de reconocer, tomando los aportes de Apfelbaum (1989), que los vínculos que se establecen entre los grupos sociales están construidos a partir de relaciones de poder. Por lo tanto, pueden pensarse en términos de conflictos por instaurar su dominio, por ocupar un territorio, por imponer sentidos a la realidad, etc. En la construcción de la identidad grupal de los grupos mayoritarios y de las minorías se despliega una lucha simbólica por establecer representaciones de sí mismos y de los demás. Tajfel (1984) explica estos procesos afirmando que los grupos construyen su propia identidad social comparándose con otros grupos, afirmando su superioridad y asociándose a valores positivos. Al mismo tiempo que se representan, representan a los demás como inferiores y relacionados con características poco favorables. Por lo tanto, los grupos minoritarios existen, en principio, en relación con las normas que establece la mayoría, es decir que se definen a partir de reglas exteriores y en función de sus carencias. Para poder generar una identidad positiva, sostiene el autor, que las minorías primeramente deben 
rechazar esta imagen elaborada e impuesta por el grupo dominante, y luego deben encontrar en su interior características relevantes que lo distingan de los demás y que puedan portar como emblema.

Como se pudo apreciar en el análisis previo, las agrupaciones de personas afectadas por la inundación lograron crear e imponer en el espacio público una representación social de sí mismos descartando la antigua representación social del inundado asociada a valores negativos. Esto fue posible por la acción movilizadora de los sectores medios afectados que, si bien no eran mayoría, tuvieron un rol central en la organización de los grupos y posicionamiento social del reclamo.

Esta nueva identidad social del inundado destacaba valores como la participación, el compromiso y la lucha (a diferencia de los anteriores que eran representados como sujetos pasivos y acostumbrados a recibir asistencia). Asimismo, se ponía en evidencia la presencia de un enunciador con cierta formación capaz de ejercer el pensamiento crítico que se observaba en las modalidades empleadas en la creación de los mensajes estético - políticos y en las referencias a otras producciones y consumos culturales. Todo ello produjo una identidad social que resultó gratificante, y que pudo ser expuesta públicamente sin temor a la crítica o la sanción del resto.

Las representaciones sociales (y las identidades), sostiene Páez (1987) retomado lo planteado por Tajfel, surgen en momentos de crisis desencadenadas por la irrupción de algún evento fuera de lo común (como es el caso de la inundación) y responden a tres necesidades que experimentan todos los grupos sociales: clasificar y comprender los acontecimientos complejos y dolorosos, realizar una diferenciación entre "nosotros" y los “otros", y finalmente justificar las acciones cometidas o planeadas contra los "otros" a fin de evitar ser sancionado.

Los grupos de personas inundadas lograron instalar socialmente su reclamo redefiniendo el fenómeno que tuvieron que enfrentar. De desastre natural, se paso a la consideración de la inundación como catástrofe política. Si bien desde un punto de vista hídrico, los eventos de 2003 y 2007 pueden explicarse por motivos ambientales y físicos, el acento puesto en la ausencia del Estado para prevenir a la población, para evitar el ingreso del agua a la ciudad, en la atención de la emergencia, y sobre todo en la falta de completamiento de la obra de defensa, hicieron que esta tragedia pueda ser interpretada como producto de los errores o incompetencia de los funcionarios provinciales y municipales. 
Asimismo, como sostiene Tajfel (1984), la identidad grupal se construye a partir de las diferencias con otros grupos. Los inundados de 2003 y 2007 se diferenciaron de los anteriores por su pertenencia a la ciudad, por su organización, su movilización social, por las intervenciones visuales (grafitis, carteles, actos y manifestaciones), por sus consumos culturales (rock, periódico Página 12, el esténcil), etc. que son todas prácticas asociadas a los sectores medios urbanos. Por otra parte, también se diferenciaron de un sector de la clase dominante al oponerse al Estado y a los funcionarios políticos, destacando su incapacidad y su inferioridad moral; construyendo en esta oposición el emblema de su lucha.

Esto les permitió aplicar sanciones para no ser sancionados. La justificación de las acciones contra el Estado se fundamentó en la incompetencia de la dirigencia para garantizar la seguridad de los habitantes. De esta manera se configuró un "otro" sobre quien recayeron las culpas, y se evitó la sanción o la crítica, que en este caso hubiera sido la identificación con el inundado anterior, asociado a la pobreza y la culpabilización por su situación.

Por otra parte, esto fue posible porque un sector de los afectados contaba con capacidades y recursos materiales y simbólicos para instalar socialmente un discurso y una representación propia, y porque este discurso estuvo asentado en esquemas similares, conocidos por la sociedad, construidos a partir de la oposición entre Estado y la población.

Este análisis puso de manifiesto los logros de estos grupos minoritarios al momento de generar una identidad positiva e instalar una representación propia del fenómeno y destacó el rol jugado por las producciones visuales al momento de representarse a sí mismos y de convocar a la adhesión de otros sectores de la sociedad. Pero también destacó las limitaciones de esta experiencia, y desveló otras problemáticas relacionadas con la situación de los grupos subalternos. ¿Qué sucede con los sectores de la sociedad que carecen de medios para promover acciones de este tipo? Que no comparten la cultura letrada de los sectores hegemónicos, que tienen otros consumos culturales, que se expresan mediante otro tipo de manifestaciones visuales, que tienen otras tradiciones, etc. ¿Cómo podrían desprenderse de las identidades negativas que les son asignadas desde afuera, para recomponer una representación de sí mismos asentada en valores propios? Este es un desafío y una aspiración, trabajar para lograr cultura y una sociedad plural y democrática, está todavía en proceso de construcción. 


\section{Referencias}

APFELBAUM, E. Relaciones de dominación y movimientos de liberación. Un análisis del poder entre los grupos, en MORALES, J. Y HUICI, C., Lecturas de Psicología Social, Madrid: UNED, pp. $261-295,1989$.

BRAVI, C. Representaciones sociales de la costa: entre el peligro y la evasión, en Espacialidades. Revista de temas contemporáneos sobre lugares, política y cultura. Volumen 3, No.2, julio-diciembre de 2013, Universidad Autónoma Metropolitana, 2013., pp. 163- 189.

CEPAL Evaluación del impacto de las inundaciones y el desbordamiento del río Salado en la provincia de Santa Fe, República Argentina en 2003, Documento elaborado por la CEPAL en cooperación con el Sistema de las Naciones Unidas en Argentina, 2003.

DE CERTEAU, M. La cultura en plural, Buenos Aires: Nueva Visión, 1999.

DIDI- HUBERMAN, G. Lo que vemos, lo que nos mira, Buenos Aires, Manantial, 2006.

GIMÉNEZ, G. Identidades sociales, México: Consejo Nacional para la Cultura y las Artes e Instituto Mexiquense de Cultura, 2009.

GIUNTA, A. Poscrisis. Arte argentino después de 2001, Buenos Aires: Siglo XXI, 2009.

GUALA, P. Inundados. Identidad que emerge con el agua, Tesis de licenciatura en Comunicación Social no publicada, Universidad Nacional de Entre Ríos, Facultad de Ciencias de la Educación, Paraná, 2005.

HABERMAS, J. Historia y crítica de la opinión pública, México: Gustavo Gili, 1986.

KOZAK, C. Contra la pared: Sobre graffiti, pintadas y otras intervenciones urbanas, Libros del Rojas, Buenos Aires, Universidad de Buenos Aires, 2004

LEFEVBRE, H. La producción del espacio, Madrid: Capitán Swing, 2013.

MASSEY, D. La filosofía y la política de la espacialidad: algunas consideraciones, en ARFUCH, L. (comp.) Pensar este tiempo. Espacios, afectos, pertenencias, Buenos Aires: Paidós, 2005, pp. 36-46.

MIRZOEFF, N. Una introducción a la Cultura Visual, Barcelona: Paidós, 2003.

MITCHELL, W.J.T Mostrando el ver. Una crítica de la cultura visual, en Revista Estudios Visuales, Número 1, Cendeac, 2003, pp. 17 - 40.

PÁEZ, D. Características, funciones y proceso de formación de las representaciones sociales, en Páez, Darío y otros Pensamiento, individuo y sociedad, Madrid: Fundamentos, 187, pp. 297-317.

PAIS, F. Agua de nadie. La historia de cómo el Salado inundó Santa Fe, Santa Fe: Ediciones UNL, 2008.

ROSSI, A. La arquitectura de la ciudad, Barcelona: Gustavo Gili, 1976. 
SPIVAK, G. Ch. ¿Puede hablar el subalterno? En revista Orbis Tertius, Volumen III, Número 6, Universidad Nacional de La Plata, 1998.

TAJFEL, H. Grupos humanos y categorías sociales, Barcelona: Herder, 1984.

ULLBERG, S. Watermarks. Urban flooding and memoryscape in Argentina, Estocolmo: Universidad de Estocolmo, 2013.

\section{Notas}

${ }^{\text {i }}$ La posición de Massey recoge y amplia los aportes de Henri Lefebvre (2013) quien establece relaciones entre la dimensión física y la social afirmando que el espacio es un soporte y un campo de acción. Es decir, lo entiende como resultado de la acción social, de las prácticas, de las relaciones y las experiencias, y la vez como una parte integrante de ellas.

ii Por ejemplo, la consolidación del peronismo fue acompañada por leyendas como "Perón sí, otro no", la resistencia peronista por "Luche y vuelve"), la lucha de los grupos armados de los setenta por "Si Evita viviera sería montonera"), la guerra de Malvinas por "Fuera yanquis de Malvinas", la ley de punto final "Ni olvido ni perdón", la política económica del neoliberalismo de los noventa por "Fuera FMI", entre otros.

iii El esténcil es una técnica que consiste en la colocación sobre la pared de plantilla calada -con letras y/o figuras- sobre la que se aplica pintura y luego se retira quedando impresa una imagen.

iv Como ejemplos de estas prácticas se puede mencionar los trabajos de los grupos Bsastencil y de BurzacoStencil. Una mención aparte merece el trabajo de la agrupación HIJOS y Grupo de Arte Callejero. Sus propuestas, presentadas en el marco de intervenciones de artísticas durante la década del noventa, buscaban marcar los sitios donde existieron centros clandestinos de detención y donde habitaban los genocidas.

v De la Psicología Social este trabajo retoma el concepto de "identidad social" propuesto por Tajfel (1984) quién la entiende como el conocimiento que tiene una persona de pertenecer a cierto grupo y la valoración social que esto conlleva, y de los Estudios Culturales, los aportes de Gilberto Giménez.

${ }^{v i}$ La obra de defensa (Terraplén Irigoyen) fue realizada en la década del cuarenta, sobre el borde oeste. Luego de los grandes daños sufridos en 1983, en los años los noventa se construyó un sistema de terraplenes que abarca la expansión de la ciudad hacia el este.

vii Sobre las causas de la inundación de 2003 ver: PAIS, F. Agua de nadie. La historia de cómo el Salado inundó Santa Fe, Santa Fe: Ediciones UNL, 2008.

viii Las causas de la inundación de 2007 se analizan en el "Informe de la Comisión Investigadora de la Inundación 2007" (Decreto H.C.M. No 441/2007), Honorable Concejo Municipal de la ciudad de Santa Fe de la Vera Cruz.

${ }^{\text {ix }}$ Estas afirmaciones plantean una serie de interrogantes que exceden el alcance de este trabajo y que se vinculan con la posibilidad de hablar del sujeto subalterno (Spivak, 1998) o con la posibilidad de existencia de la cultura popular por fuera del acto que la suprime (de Certeau, 1999).

${ }^{x}$ Los afiches fueron realizados por dos jóvenes afectados por la inundación integrantes de la Asamblea Permanente de Afectados por la Inundación y fueron impresos en la imprenta de una integrante del grupo Marcha de las Antorchas con dinero propio del grupo (Guala, 2005).

${ }^{x i}$ Este planteamiento se sustentaba en los estudios técnicos que afirmaban que de haber estado concluida esta obra, la ciudad no se hubiera anegado en las proporciones que lo hizo y el agua hubiera entrado más lentamente dando tiempo a evacuar las viviendas

xii Siguiendo lo planteado por Kozak (2004) para el caso de Buenos Aires, la elección de la técnica del esténcil supone una persona con ciertas habilidades y conocimientos para desarrollar la práctica, lo que ubicaría a los realizadores, entre los sectores medios urbanos. 


\section{Sobre a autora}

Carolina Anabel Bravi. Arquitecta. Licenciada en Artes Visuales. Doctora en Ciencias Sociales. Docente investigadora de la Universidad Nacional del Litoral (UNL) y de la Universidad Autónoma de Entre Ríos (UADER). Miembro del Centro de Investigaciones en Estudios Culturales, Educativos, Históricos y Comunicacionales (CIECEHC) de la UNL. Integrante Proyecto de Investigación CAI+D «Historia memorias y representaciones de pasado reciente: gubernamentalidades, violencia política y derechos humanos» de la UNL. Ha publicado artículos en revistas nacionales e internacionales sobre temáticas relacionadas con la significación de las imágenes en el cine y la fotografía. Correo Electrónico: carolinabravi@gmail.com 